Supplemental Information

\title{
Sources of Fine Particles in a Rural Midwestern U.S. Area
}

\author{
Eugene Kim, Philip K. Hopke, Donna M. Kenski, Michael Koerber
}

Table S1. Source profiles deduced by PMF.

\begin{tabular}{|c|c|c|c|c|c|c|c|c|}
\hline Species & $\begin{array}{c}\text { Secondary } \\
\text { sulfate I }\end{array}$ & $\begin{array}{l}\text { Secondary } \\
\text { nitrate }\end{array}$ & $\begin{array}{l}\text { Gasoline } \\
\text { vehicle }\end{array}$ & $\begin{array}{c}\text { Secondary } \\
\text { sulfate II }\end{array}$ & $\begin{array}{l}\text { Secondary } \\
\text { sulfate III }\end{array}$ & $\begin{array}{c}\text { Airborne } \\
\text { soil }\end{array}$ & $\begin{array}{l}\text { Aged sea } \\
\text { salt }\end{array}$ & $\begin{array}{c}\text { Diesel } \\
\text { emissions }\end{array}$ \\
\hline OC1 & 0.00254 & 0.00313 & 0.02225 & 0.00889 & 0.02252 & 0.00312 & 0.01170 & 0.00084 \\
\hline OC2 & 0.02307 & 0.00523 & 0.08727 & 0.03411 & 0.06240 & 0.00418 & 0.01921 & 0.01614 \\
\hline OC3 & 0.01136 & 0.00372 & 0.33212 & 0.00008 & 0.09061 & 0.02098 & 0.00511 & 0.05149 \\
\hline OC4 & 0.02131 & 0.01605 & 0.22760 & 0.00014 & 0.09514 & 0.01333 & 0.04483 & 0.04308 \\
\hline OP & 0.00129 & 0.00001 & 0.00001 & 0.18830 & 0.00041 & 0.00045 & 0.00096 & 0.00003 \\
\hline EC1 & 0.01641 & 0.01802 & 0.11687 & 0.00010 & 0.06560 & 0.00007 & 0.00274 & 0.10686 \\
\hline EC2 & 0.00203 & 0.00005 & 0.00003 & 0.06971 & 0.03179 & 0.00321 & 0.00008 & 0.04150 \\
\hline EC3 & 0.00000 & 0.00000 & 0.00277 & 0.00728 & 0.00000 & 0.00000 & 0.00000 & 0.00061 \\
\hline S & 0.17247 & 0.03511 & 0.00013 & 0.16200 & 0.15079 & 0.00116 & 0.00299 & 0.04482 \\
\hline $\mathrm{NO}_{2}$ & 0.00084 & 0.00001 & 0.00186 & 0.00587 & 0.00005 & 0.00001 & 0.00008 & 0.00744 \\
\hline $\mathrm{NO}_{3}$ & 0.00042 & 0.62915 & 0.00228 & 0.01692 & 0.00110 & 0.04237 & 0.52503 & 0.02175 \\
\hline $\mathrm{Al}$ & 0.00016 & 0.00068 & 0.00060 & 0.00002 & 0.00008 & 0.01177 & 0.00404 & 0.00036 \\
\hline As & 0.00001 & 0.00001 & 0.00005 & 0.00006 & 0.00032 & 0.00000 & 0.00000 & 0.00021 \\
\hline $\mathrm{Br}$ & 0.00008 & 0.00009 & 0.00064 & 0.00007 & 0.00066 & 0.00001 & 0.00364 & 0.00000 \\
\hline $\mathrm{Ca}$ & 0.00000 & 0.00000 & 0.01551 & 0.00927 & 0.00001 & 0.03498 & 0.00003 & 0.01885 \\
\hline $\mathrm{Cl}$ & 0.00001 & 0.00000 & 0.00006 & 0.00017 & 0.00013 & 0.00005 & 0.00013 & 0.00021 \\
\hline $\mathrm{Cl}^{-}$ & 0.00001 & 0.00478 & 0.01141 & 0.02221 & 0.00185 & 0.00008 & 0.00079 & 0.03479 \\
\hline $\mathrm{Cr}$ & 0.00000 & 0.00000 & 0.00000 & 0.00000 & 0.00001 & 0.00000 & 0.00005 & 0.00031 \\
\hline $\mathrm{Cu}$ & 0.00002 & 0.00004 & 0.00015 & 0.00005 & 0.00012 & 0.00004 & 0.00002 & 0.00090 \\
\hline $\mathrm{Fe}$ & 0.00074 & 0.00013 & 0.00250 & 0.00025 & 0.00545 & 0.05762 & 0.00713 & 0.04408 \\
\hline $\mathrm{H}$ & 0.06140 & 0.04670 & 0.04282 & 0.06985 & 0.06332 & 0.00146 & 0.00031 & 0.00416 \\
\hline K & 0.00042 & 0.00138 & 0.01802 & 0.00550 & 0.00165 & 0.02530 & 0.00832 & 0.01116 \\
\hline $\mathrm{Mg}$ & 0.00003 & 0.00046 & 0.00100 & 0.00370 & 0.00002 & 0.00004 & 0.00472 & 0.00287 \\
\hline Mn & 0.00000 & 0.00000 & 0.00000 & 0.00000 & 0.00000 & 0.00049 & 0.00080 & 0.00389 \\
\hline $\mathrm{Na}$ & 0.00000 & 0.00000 & 0.00001 & 0.00002 & 0.00002 & 0.00001 & 0.21362 & 0.00703 \\
\hline $\mathrm{Ni}$ & 0.00001 & 0.00000 & 0.00000 & 0.00000 & 0.00000 & 0.00002 & 0.00021 & 0.00014 \\
\hline $\mathrm{Pb}$ & 0.00000 & 0.00000 & 0.00013 & 0.00020 & 0.00497 & 0.00011 & 0.00075 & 0.00322 \\
\hline $\mathrm{Rb}$ & 0.00000 & 0.00000 & 0.00002 & 0.00005 & 0.00000 & 0.00011 & 0.00009 & 0.00011 \\
\hline Se & 0.00014 & 0.00001 & 0.00007 & 0.00020 & 0.00071 & 0.00002 & 0.00008 & 0.00051 \\
\hline $\mathrm{Si}$ & 0.01077 & 0.00000 & 0.01544 & 0.01185 & 0.00002 & 0.16323 & 0.00376 & 0.00057 \\
\hline $\mathrm{Sr}$ & 0.00001 & 0.00000 & 0.00004 & 0.00009 & 0.00000 & 0.00038 & 0.00019 & 0.00000 \\
\hline $\mathrm{Ti}$ & 0.00013 & 0.00000 & 0.00012 & 0.00000 & 0.00018 & 0.00700 & 0.00000 & 0.00000 \\
\hline V & 0.00004 & 0.00000 & 0.00006 & 0.00000 & 0.00000 & 0.00020 & 0.00006 & 0.00000 \\
\hline $\mathrm{Zn}$ & 0.00000 & 0.00066 & 0.00185 & 0.00000 & 0.00201 & 0.00000 & 0.00001 & 0.01578 \\
\hline $\mathrm{Zr}$ & 0.00000 & 0.00000 & 0.00000 & 0.00006 & 0.00002 & 0.00004 & 0.00008 & 0.00007 \\
\hline
\end{tabular}




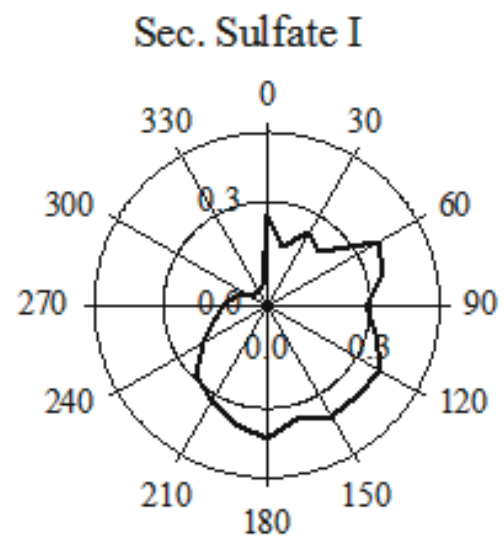

Sec. Sulfate II

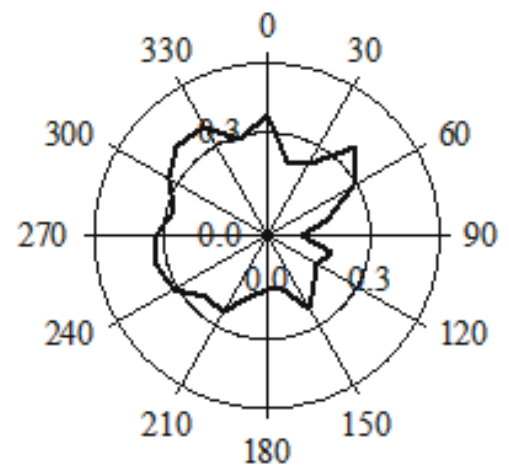

Aged sea salt

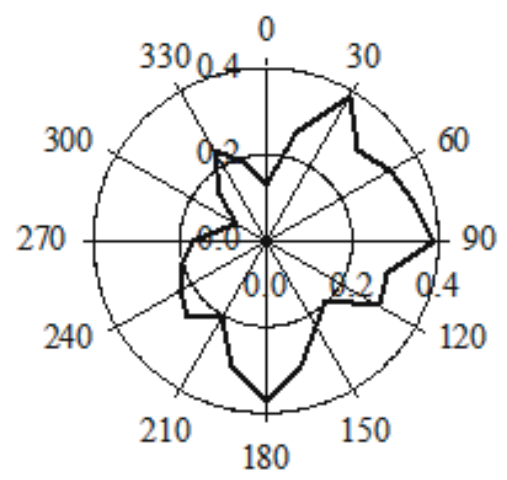

Sec. nitrate

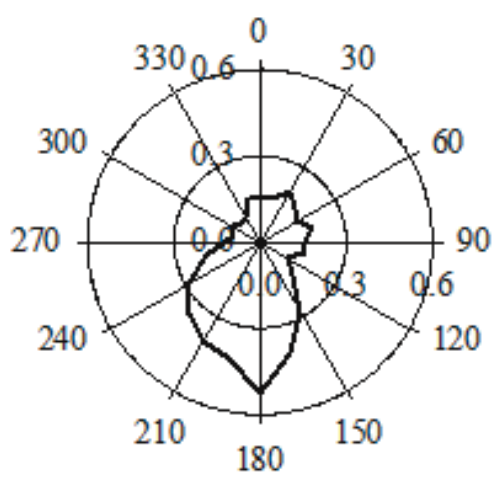

Sec. Sulfate III

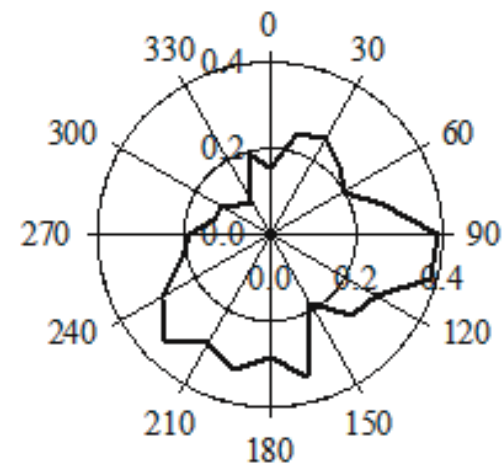

Diesel emissions

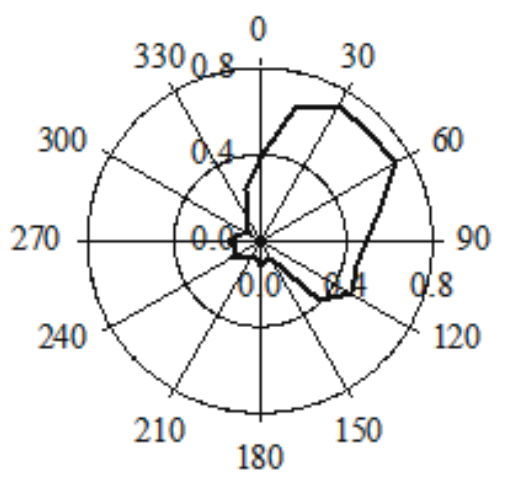

Figure S1. CPF plots for the highest $25 \%$ of the mass contributions. 